\section{A LEGISLAÇÃO AMBIENTAL APLICADA AOS PRODUTORES RURAIS}

Adriana Maria Risso Caires Silva Mario Marcos Lopes ${ }^{2}$

João Francisco Othon Teixeira ${ }^{3}$ Antonio Carlos Fuzaro Junior ${ }^{4}$

Resumo: Os recursos naturais estão sendo cada vez mais explorados de maneira predatória propiciada pelo modelo econômico em que estamos inseridos, modelo este que visa o lucro, gerado a partir de produtos retirados da natureza, seja direta ou indiretamente. Esse fato resultou com que o sistema culminasse na crise financeira e ideológica que permeia a sociedade contemporânea. Habitualmente as preocupações são tantas que afetam o modo de vida e até as relações com o meio ambiente. A legislação ambiental reflete estas preocupações apresentando regras mais claras que orientam as atividades humanas, buscando garantir qualidade ambiental para toda a sociedade. No Brasil as leis ambientais estão documentadas, basicamente, na Constituição Federal, no Código Florestal Brasileiro, na Lei de Crimes Ambientais, além de outras normativas. Portanto, esse trabalho, de cunho bibliográfico, tem por objetivo interpretar a legislação relativa ao Meio Ambiente para o produtor rural, para que possa desenvolver suas atividades dentro dos padrões legais. Serão apresentadas, a legislação ambiental brasileira quanto ao recursos hídricos, o uso e ocupação do solo, principalmente em relação às Áreas de Preservação Permanente e Áreas de Reserva Legal, de acordo com a Lei no. 12.651, de 25 de maios de 2012, oriundo do Projeto de Lei n ${ }^{\circ} 1.876 / 99$. Entretanto, a letra da lei por si só não basta, são necessários instrumentos legais que garantam sua aplicabilidade, tais como a necessidade de imposição de multas, em caso de desrespeito, e fiscalização constante.

Palavras-Chave: Legislação; Meio Ambiente; Produtor Rural.

Mestre em Desenvolvimento Regional e Meio Ambiente - Universidade de Araraquara. Docente no Instituto Municipal de Ensino Superior de Catanduva - Imes Catanduva.

Mestre em Desenvolvimento Regional e Meio Ambiente - Universidade de Araraquara. Professor/tutor da Faculdade de Educação São Luís de Jaboticabal e Universidade Federal de São Paulo - Unifesp. Docente do Centro Universitário Barão de Mauá - Ribeirão Preto/SP.

Mestre em Desenvolvimento Regional e Meio Ambiente - Universidade de Araraquara. Docente no Instituto Municipal de Ensino Superior de Catanduva - Imes Catanduva.

${ }^{4}$ Mestre em Administração - Centro Universitário Moura Lacerda. Professor de Direito Empresarial e Direito Ambiental no Instituto Municipal de Ensino Superior de Catanduva - Imes Catanduva.
Abstract: Natural resources are being increasingly exploited in a predatory way provided by the economic model in which we are inserted, this model that aims at profit, generated from products taken from nature, either directly or indirectly. This resulted in the system culminating in the financial and ideological crisis that pervades contemporary society. Usually the concerns are so many that affect the way of life and even the relations with the environment. Environmental legislation reflects these concerns by presenting clearer rules that guide human activities, seeking to ensure environmental quality for the whole society. In Brazil, environmental laws are basically documented in the Federal Constitution, the Brazilian Forest Code, the Environmental Crimes Law, and other regulations. Therefore, this bibliographical work aims to interpret the legislation related to the Environment for the rural producer, so that it can develop its activities within the legal standards. The Brazilian environmental legislation on land use and occupation will be presented, mainly in relation to the Permanent Preservation Areas and Legal Reserve Areas, in accordance with Law 12.651, of May 25, 2012, arising from Draft Law 1.876/99. However, the letter of the law alone is not enough, legal instruments are needed to ensure its applicability, such as the need to impose fines, in case of disrespect, and constant supervision.

Keywords: Legislation; Environment; Rural producer.

\section{Introdução}

Os sistemas convencionais de produção agropecuária são considerados grandes causadores de impactos ambientais, assim como, a degradação do solo, a poluição e assoreamento dos rios, a destruição da vegetação nativa, a perda da biodiversidade, além da contaminação de alimentos, o que consequentemente, induz o aparecimento dos problemas sociais, econômicos e ambientais.

Waldman (2007) menciona que os recursos naturais estão sendo explorados de maneira predatória, sendo que a maior causa disso é o modelo econômico em que estamos inseridos, modelo este, que visa o lucro, gerado a partir de produtos retirados da natureza, seja direta ou indiretamente. Isso fez com que o sistema culminasse na crise financeira e ideológica que permeia a sociedade contemporânea. Essa crise possui dimensões gigantescas, que afeta o modo de vida e até as relações com o meio ambiente (KAPRA, 2005). 
Esse modelo predominante de produção agropecuária, embora tenha aumentado à produtividade rural, tem sido apontado como responsável pelos impactos gerados sobre o meio ambiente, como o comprometimento de recursos hídricos e do solo, e sobre a sociedade, com a expulsão do pequeno produtor das áreas rurais (MOREIRA, 2000).

A preocupação com as questões ambientais está cada vez mais presente nos diversos setores da sociedade brasileira. A legislação ambiental reflete estas preocupações apresentando regras mais claras que orientam as atividades humanas, buscando garantir qualidade ambiental para toda a sociedade brasileira. As leis ambientais foram instituídas com o objetivo de disciplinar o uso e a ocupação do solo e dos demais recursos naturais (água, florestas, ar, entre outros).

A elaboração de Leis para proteção do meio Ambiente se tornou evidente a partir do momento em que se percebeu que os recursos naturais não eram infinitos e o uso desenfreado desses recursos estava ocasionando sérios danos como o aumento de doenças nas lavouras; o esgotamento dos solos reduzindo sua produtividade e sendo necessário, a cada ano maiores quantidades de adubos e calcário; o surgimento de várias doenças em seres humanos, como doenças respiratórias causadas pela poluição e intestinais causadas pela água contaminada, entre outras.

A partir disso, as autoridades começaram a elaborar leis ambientais para tentar reduzir esses impactos, os quais geravam efeitos negativos ao meio ambiente. No Brasil, as leis ambientais estão documentadas, fundamentalmente, na Constituição Federal, no Código Florestal Brasileiro, na Lei de Crimes Ambientais, além de outras normativas.

A Lei Federal é comum a todos, porém cada Estado pode elaborar leis próprias, desde que não fira o preceito Constitucional. É válido lembrar que para cada município dos entes federativos, existe uma lei orgânica (Constituição Municipal eos Conselhos deDesenvolvimentodoMeioAmbiente-CODEMAs).

No entanto, as externalidades positivas ${ }^{5}$ decorrentes da produção não são valorizadas pela sociedade e nem revertidas em renda para o produtor. Dentro desse contexto, a proposta dessa pesquisa é interpretar a legislação do meio ambiente ao produtor rural, de maneira prática, inserindo o conceito de multifuncionalidade para desenvolver suas atividades dentro dos padrões legais, conforme a legislação vigente, a qual poderá ser uma estratégia

${ }^{5}$ Quando determinado agricultor, através de um mecanismo que o auxilie na preservação ambiental, obtêm tecnologia a baixo custo na solução de problemas ampliando o cultivo sem degradar o meio ambiente. para agregar renda aos produtores familiares, mantendo a sustentabilidade ambiental na agricultura.

Será apresentada, a legislação ambiental brasileira aplicada aos produtores rurais quanto ao uso e ocupação do solo, principalmente em relação às Áreas de Preservação Permanente - APPs e Áreas de Reserva Legal - RL, de acordo com a Lei $\mathrm{n}^{\circ} .12 .651$, de 25 de maio de 2012, oriundo do Projeto de Lei ${ }^{\circ} 1.876 / 99$.

Com isso, busca-se propor ações de suporte institucional para a viabilização dessa estratégia, tendo como parâmetro a metodologia de mensuração dos benefícios sociais, econômicos e ambientais decorrentes de uma gestão holística dos recursos naturais no ambiente rural.

\section{Meio Ambiente e a Constituição Federal Brasileira - 1988}

No Brasil, o tratamento dado ao meio ambiente pela Constituição Federal de 1988 está relacionado à nossa visão do meio ambiente como direito fundamental, a conservação da diversidade biológica e dos processos ecológicos, a criação de espaços territoriais especialmente protegidos, a necessidade de estudo prévio de impacto ambiental antes da realização de atividades potencialmente causadoras de significativa degradação, além da educação ambiental.

A Constituição Federal de 1988 foi a primeira a dedicar, exclusivamente, um capítulo a proteção do Meio ambiente, e em seu artigo 225, define as responsabilidades e os deveres de cada cidadão com a proteção do meio ambiente.

Art.225 - Todos têm direito ao meio ambiente ecologicamente equilibrado, bem de uso comum do povo e essencial à sadia qualidade de vida, impondo-se ao Poder Público e a coletividade o dever de defendê-lo e preservá-lo para presentes e futuras gerações.

Com base nisso, percebe-se que o citado dispositivo está revestido de uma "natureza dúplice", ou seja, o direito ao meio ambiente ecologicamente equilibrado para as presentes e futuras gerações é, ao mesmo tempo, direito e dever fundamental do Poder Público e de toda coletividade.

Quanto a natureza dúplice, citamos que o meio ambiente é de interesse coletivo ou direito difuso, o qual a tutela do meio ambiente o coloca na condição de direito metaindividual ou coletivo lato sensu, ou seja, daquele que está acima dos interesses individuais. 
Esses interesses "metaindividuais" são encontrados em uma posição intermediária localizada entre os interesses públicos e privados. São aqueles que ultrapassam a esfera meramente individual do particular, uma vez que são vinculados a um grupo, classe ou categoria de pessoas (MAZILLI, 2012).

Segundo Bonavides (1993), o direito fundamental ao meio ambiente equilibrado, decorre diretamente do direito à vida, em sua acepção qualidade de vida, ao contrário dos direitos fundamentais individuais e sociais, traz como principais características a transindividualidade ${ }^{6}$, tendo por destinatário todo o gênero humano.

Sua desvinculação de critérios patrimoniais e o abandono da ideia tradicional de direito subjetivo, que demanda a individualização de um titular. (BARROSO, 1993).

Desse modo, oportunas são as palavras de Ferreira Filho (1997, p.102), o qual discorre que "o direito ao meio ambiente equilibrado é um direito de solidariedade, pertencente à terceira geração de direitos fundamentais, provindo do direito à vida, por intermédio do direito à saúde".

Desse modo, quando se pretende defender o ambiente sadio, não é possível fazê-lo apenas para uma ou para algumas pessoas, a obrigação e responsabilidade está dividida entre o Poder Público e a sociedade.

Desta forma foi necessário inserir artigos deliberando as competências para legislar e administrar. Assim, a União, os Estados, o Distrito Federal e os Municípios, possuem competência e autoridade para tratar do meio ambiente de forma independente, seguindo nossa Carta Magna. As Competências Ambientais estão descritas da seguinte forma:

Art.22 - É competência privativa da União, legislar sobre as matérias relacionadas com as águas, energia, populações indígenas, jazidas e outros recursos minerais, além das atividades nucleares de qualquer natureza, salvo edição de lei complementar.

Art.23 - A competência comum é relativa a várias entidades, que são elas a União, Estados, Municípios e o Distrito Federal, onde estes entes devem agir de forma integrada, buscando alcançar os objetivos descritos na Constituição Federal.

Art.24 - Em relação à competência concorrente compete à União, aos Estados e ao Distrito Federal legislar concorrentemente sobre

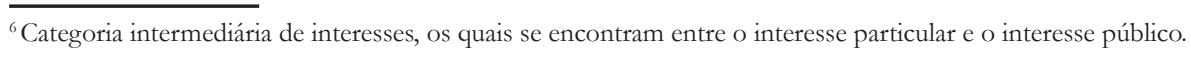

possibilidade de União, Estados, Municípios e DF disporem sobre o mesmo assunto ou matéria, sendo que a União legisla sobre normas gerais.

Art.30 - Compete aos Municípios, legislar sobre assuntos de interesse local e suplementar a legislação federal e a estadual no que couber.

Desta forma, a Constituição Federal no $\S 1^{\circ}$ do artigo 225 , cita que:

Como meio de assegurar a efetividade do direito de todos ao meio ambiente ecologicamente equilibrado, prestações materiais e atuação legislativa, a que concorrem os três entes federativos, no âmbito de suas respectivas competências.

Não basta apenas que o legislador constituinte tenha deixado consignada a proteção ao meio ambiente. Cabe a todos os cidadãos e às autoridades responsáveis, o trabalho de tirar as normas ambientais da teoria e trazêlas para a existência efetiva da vida real, inclusive através da promoção da educação ambiental desde a infância, tendo em vista que a utilização adequada dos recursos naturais disponíveis e a preservação do meio ambiente são indispensáveis para um desenvolvimento socioeconômico saudável e sustentável (MILARÉ, 2000).

Assim, foi inserido no ordenamento jurídico brasileiro uma nova categoria de bem juridicamente tutelado, ou seja, o direito ao meio ambiente ecologicamente equilibrado, um bem de uso comum do povo, e, ainda, um bem essencial à sadia qualidade de vida.

Nesse contexto, é dever de todos os entes federativos proteger o meio ambiente e combater todas as formas de poluição, proteger os monumentos, as paisagens naturais notáveis e os sítios arqueológicos, preservar as florestas, a fauna e a flora, bem como registrar, acompanhar e fiscalizar as concessões de direitos de pesquisa e exploração de recursos hídricos e minerais em seus territórios. Essa competência comum permite que todos os entes federativos fiscalizem e imponham sanções pelo descumprimento da legislação ambiental.

Existem vários outros dispositivos que versam sobre a proteção ao meio ambiente, mas aliado à proteção legal deve existir a fiscalização ambiental e a educação ambiental que juntas garantirão aplicação da legislação.

\section{Área de preservação ambiental - APA}


Originalmente criado pela Lei 6902/1981, as Áreas de Proteção Ambiental - APA, são reguladas pela Lei 9.985/00, o Sistema Nacional de Unidades de Conservação da Natureza - SNUC.

Assim, podemos dizer que a APA é uma extensa área natural destinada à proteção e conservação da fauna e flora, importantes para a qualidade de vida da população daquela região, bem como, para a proteção dos ecossistemas regionais. O objetivo principal de uma APA é a conservação de processos naturais e da biodiversidade, através da orientação, do desenvolvimento, além de adequar-se daquelas atividades humanas às características ambientais da área.

Como unidade de conservação da categoria uso sustentável, a APA permite a ocupação humana. Estas unidades existem para conciliar a ordenada ocupação humana da área e o uso sustentável dos seus recursos naturais. A ideia do desenvolvimento sustentável direciona toda e qualquer atividade a ser realizada na área.

\section{Estudo de impacto ambiental/EIA e Relatório de impacto ambiental/RIMA}

O Estudo de Impacto Ambiental - EIA pressupõe o controle preventivo de danos ambientais. Uma vez constatado o perigo ao meio ambiente, deve-se ponderar sobre os meios de evitar ou minimizar o prejuízo. É um instrumento de caráter constitucional que ocorre no âmbito do processo de licenciamento ambiental. A Constituição Federal estabeleceu que entre as competências do Poder Público, a fim de assegurar o direito ao meio ambiente ecologicamente equilibrado, cita:

Art. 225. Todos têm direito ao meio ambiente ecologicamente equilibrado, bem de uso comum do povo e essencial à sadia qualidade de vida, impondo-se ao Poder Público e à coletividade o dever de defendê-lo e preservá-lo para as presentes e futuras gerações.

$\S 1^{\circ}-\ldots .$.

I - .......;

II - .....;

III - ......;

IV - exigir, na forma da lei, para instalação de obra ou atividade potencialmente causadora de significativa degradação do meio ambiente, estudo prévio de impacto ambiental, a que se dará publicidade;
A Resolução CONAMA n ${ }^{\circ}$ 1, de 1986, exige realização de Estudo de Impacto Ambiental/EIA e respectivo Relatório de Impacto Ambiental RIMA, para o licenciamento de atividades que venham a modificar o meio ambiente. Observa-se nessa oportunidade que a norma constitucional tornou-se mais técnica a questão de qualquer atividade humana que venha a modificar o ambiente, sem necessariamente causar danos.

$\mathrm{O}$ que se deve depender do EIA são aquelas atividades que venham a causar impactos ambientais significativos (danos certos ou incertos), apesar da presente Resolução (Resolução CONAMA n ${ }^{\circ}$ 1, de 23-01-1986), que estabelece um rol exemplificativo dos empreendimentos sujeitos ao EIA/ RIMA, cabendo ao Órgão licenciador ou ao Ministério Público, determinar ou não a execução do EIA/RIMA de acordo com a complexidade do projeto.

Nos termos do artigo $1^{\circ}$ da Resolução CONAMA ${ }^{\circ} 1 / 86$, podemos dizer que, considera-se impacto ambiental qualquer alteração das propriedades físicas, químicas e biológicas do meio ambiente, causada por qualquer forma de matéria ou energia resultante das atividades humanas que, direta ou indiretamente, afetam a saúde, a segurança e o bem-estar da população, as atividades sociais e econômicas, a biota, as condições estéticas e sanitárias do meio ambiente e a qualidade dos recursos ambientais.

O estudo prévio de impacto ambiental deve ter como objetivo compatibilizar o desenvolvimento econômico-social com a preservação da qualidade do meio ambiente e do equilíbrio ecológico, tendo em vista constituir um dos principais objetivos da Política Nacional do Meio Ambiente - Lei 6.938/81, art. $4^{\circ}$, I. (SILVA, 1994)

Desta forma, a apresentação de um EIA/RIMA favorável, vincula o órgão público a conceder a licença ambiental, haja vista que sendo a defesa do meio ambiente condicionada a livre iniciativa, nos termos do art. 170, VI, da Constituição Federal, não existindo nenhuma forma de prejuízo ao bem ambiental, não havendo justificativa para impedir a realização da obra ou atividade.

O Relatório de Impacto Ambiental (RIMA) tem como finalidade esclarecer o conteúdo do estudo de impacto ambiental realizado, uma vez que este documento é elaborado em termos técnicos. Uma vez elaborado, o EIA/RIMA deverão ser dirigidos ao órgão ambiental competente para que se proceda ao deferimento da licença ambiental ou não.

\section{Pontos relevantes do Código Florestal Brasileiro}


Primeiramente é importante destacar que a intervenção do direito em matéria ambiental seria desnecessária se a sociedade, como um todo, fosse capaz de entender que qualquer espécie de vida existente no planeta depende, exclusivamente, do meio ambiente natural, portanto, também de sua sustentabilidade.

O ramo do Direito Ambiental é um conjunto de princípios e normas que sancionam as atividades humanas que venham lesar o meio ambiente, independentemente do fato de que estas ocorram de forma direta ou indireta.

Fatores como os climáticos e biológicos são de extrema importância para o equilíbrio ambiental, bem como aqueles que se destinam à contenção de ruídos ou à preservação do verde, os quais são considerados valores básicos à sobrevivência humana. Sendo assim, é dever da coletividade preservá-los, com a devida consciência em relação a sua essencialidade para a vida do ser humano, sendo incumbência do Poder Público promover sua defesa (ALVES, 2016).

Recentemente o Código Florestal Brasileiro sofreu alterações, haja vista que estava em vigor desde 1965. As principais diferenças, básicas, entre o Código Florestal anterior (Lei ${ }^{\circ} 4.771$, de 15 de setembro de 1965) e o atual Código Florestal vigente (Lei n. 12.651, de 25 de maio de 2012) são descritos no Quadro 1:

O artigo 15 do Novo Código Florestal possui grande importância, pois reduz a perda das áreas agricultáveis, autorizando o proprietário rural a compensar as APPs para calcular a sua área de RL, a preocupação maior com a mudança deste artigo, foi à manutenção e a preservação de áreas de matas, surgindo desta forma corredores ecológicos ${ }^{7}$, para manter a biodiversidade de uma determinada região.

A APP diz respeito àquelas áreas que desta forma estão definidas no Código Florestal, o qual proíbe alterações promovidas pelo homem, bem como de qualquer interferência sobre o meio ambiente, tais como desmatamento ou construção. Sendo permitidas nessas áreas, apenas as práticas de atividades de laser e de se alimentar com frutos das árvores. Desta forma, configura-se crime qualquer modificação nessas áreas.

Antes da mudança do Código Florestal, os produtores poderiam usufruir deste benefício nos casos onde as áreas de APP e RL fossem superiores a $80 \%$

\footnotetext{
Porções de ecossistemas naturais ou seminaturais, que ligam Unidades de Conservação, possibilitando entre elas o fluxo de genes e o movimento da biota, facilitando a dispersão de espécies e a recolonização de área degradadas, bem como a manutenção de populações que demandam para sua sobrevivência áreas com extensão maior do que aquela das unidades individuais (BRASIL, 2002 apud UMEDA et al., 2015).
}

Quadro 1 - Comparação entre os Códigos Florestais de 1965 e 2012.

\begin{tabular}{|c|c|c|c|c|}
\hline Temas & Reserva Legal (RL) & $\begin{array}{c}\text { Áreas de Preservação } \\
\text { Permanente (APP) }\end{array}$ & Área rural consolidada & Anistia \\
\hline \begin{tabular}{|l} 
Código \\
Florestal \\
$(1965)$
\end{tabular} & 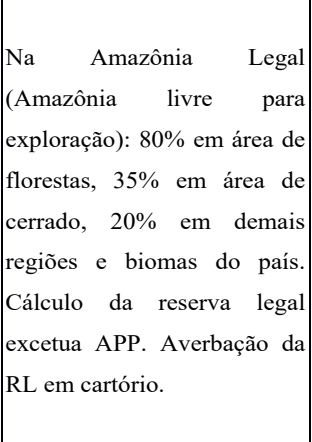 & $\begin{array}{l}\text { Proteção da vegetação } \\
\text { nativa de margens de rios, } \\
\text { lagos e } \\
\text { comoscentes, } \\
\text { condono parâmetro o período } \\
\text { de cheia. Varzeas, } \\
\text { mangues, matas de } \\
\text { encostas, topos dos morros } \\
\text { e áreas com altitude } \\
\text { superior a } 1800 \text { metros não } \\
\text { podem ser exploradas para } \\
\text { atividades econômicas. }\end{array}$ & $\begin{array}{l}\text { Não contempla conceito de } \\
\text { área consolidada. } \\
\text { Recomposição, } \\
\text { regeneração e } \\
\text { compensação são } \\
\text { obrigatórias. }\end{array}$ & $\begin{array}{l}\text { Pena de três meses a } \\
\text { um ano de prisão } \\
\text { simples e multa de } 1 \text { a } \\
100 \text { vezes o salário- } \\
\text { mínimo. }\end{array}$ \\
\hline \begin{tabular}{|l} 
Código \\
Florestal \\
(2012)
\end{tabular} & $\begin{array}{l}\text { Na Amazônia Legal: } 80 \% \text { em } \\
\text { área de florestas, } 35 \% \text { em área } \\
\text { de cerrado, } 20 \% \text { em demais } \\
\text { regiões e biomas do país. } \\
\text { Cálculo da reserva inclui a } \\
\text { APP. Imóveis de até quatro } \\
\text { módulos fiscais não precisam } \\
\text { recompor a RL. Fim da } \\
\text { exigência de averbação da RL } \\
\text { em cartório foi criado o } \\
\text { Cadastro Ambiental Rural - } \\
\text { CAR, no âmbito do Sistema } \\
\text { Nacional de Informação sobre } \\
\text { Meio Ambiente - SINIMA, } \\
\text { registro público eletrônico de } \\
\text { âmbito nacional, obrigatório } \\
\text { para todos os imóveis rurais, } \\
\text { com a finalidade de integrar } \\
\text { as informações ambientais } \\
\text { das propriedades e posses } \\
\text { rurais, compondo base de } \\
\text { dados para controle, } \\
\text { monitoramento, planejamento } \\
\text { ambiental e econômico e } \\
\text { combate ao desmatamento. } \\
\text { Permissão de exploração } \\
\text { econômica da RL com } \\
\text { autorização do Sisnama. }\end{array}$ & \begin{tabular}{|l} 
Proteção da vegetação \\
nativa de margens de rios, \\
lagos e nascentes, tendo \\
como parâmetro o nível \\
regular da água. Várzeas, \\
mangues, matas $\quad$ de \\
encostas, topos dos morros \\
e áreas com altitude \\
superior a 1800 metros \\
podem ser utilizadas para \\
determinadas atividades \\
econômicas. \\
\\
\end{tabular} & 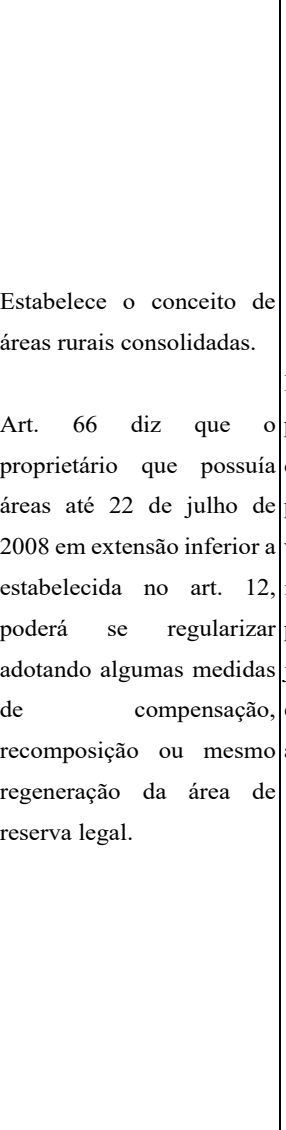 & 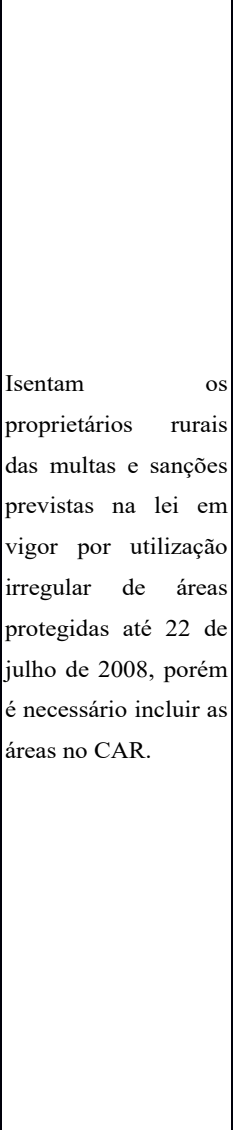 \\
\hline
\end{tabular}

Fonte: elaborado pelos autores. 
(oitenta por cento) em propriedades da Amazônia Legal e 50\% (cinquenta por cento) nas outras regiões do Brasil.

Com a implantação desta mudança, algumas exigências foram admitidas para o cálculo que são: a não conversão de novas áreas para o uso alternativo do solo; o computo da área deverá estar conservada ou em processo de recuperação, conforme comprovação do proprietário junto ao órgão estadual integrante do Sisnama; e o proprietário ou possuidor tenha requerido inclusão do imóvel no Cadastro Ambiental Rural - CAR.

O legislador pátrio, ao conceituar de APP visou resguardar diretamente os recursos naturais e a garantia do equilíbrio do meio ambiente e, por consequência a manutenção da vida humana. Eliminando assim, a possibilidade de degradação por causa do desenvolvimento econômico.

As alterações trazidas pelo novo Código Florestal necessitam de um melhor entendimento do meio ambiente como um todo. Para entender o Código Florestal é necessário entender o seu princípio básico, escrito no Artigo $2^{\circ}$ :

Art. $2^{\circ}$ - As florestas existentes no território nacional e as demais formas de vegetação nativa, reconhecidas de utilidade às terras que revestem, são bens de interesse comum a todos os habitantes do País, exercendo-se os direitos de propriedade com as limitações que a legislação em geral e especialmente esta Lei estabelecem.

$\mathrm{O}$ artigo considera as florestas como um bem público, dessa forma todas as pessoas possuem direito e responsabilidades sobre elas. Como já observado na Constituição, as florestas pertencem ao meio ambiente e devem ser preservadas. Assim, quando alguém se sentir prejudicado como no caso de um desmatamento ou queimada criminosa, poderá denunciar os responsáveis. Isso porque mesmo que a floresta se localize em uma propriedade privada, ela não é apenas do proprietário, mas pertencente a todos, ou seja, qualquer pessoa poderá denunciar a agressão a quaisquer formas de vegetação (cerrado, caatinga, brejo, campo, etc.).

Basicamente, as florestas estão protegidas pelo Código Florestal divididas em categorias, assim como:

- Unidades de Conservação, sendo áreas destinadas à proteção dos recursos naturais (plantas, animais, água e solo) visando atender às necessidades humanas. Existem várias categorias de unidades de conservação, com diferentes usos, tais como parques, reservas biológicas, áreas de proteção ambiental e Reservas Particulares do Patrimônio Natural
(RPPN). As unidades de conservação podem ser municipais, estaduais, federais e particulares.

- Reserva Particular do Patrimônio Natural trata-se de uma área protegida, instituída em propriedades de domínio privado por iniciativa de seus proprietários, mediante ato de reconhecimento do Poder Público por ser consideradas de relevante importância para a proteção da biodiversidade, mesmo que, embora degradadas, possuam características que justifiquem ações de recuperação de modo a promover a conservação de seu ecossistema; ou também por apresentarem atributos de caráter paisagísticos que mereçam sua preservação.

- Áreas de Preservação Permanente (APP) área protegida, coberta ou não por vegetação nativa, com a função ambiental de preservar os recursos hídricos, a paisagem, a estabilidade geológica e a biodiversidade, facilitar o fluxo gênico de fauna e flora, proteger o solo e assegurar o bem-estar das populações humanas; são áreas que, de acordo com a sua localização, em regra devem ser mantidas protegidas, não sendo permitido o corte ou exploração da floresta ou da vegetação que a cobre, a exceção para sua utilização se dá quando houver caso de utilidade pública, interesse social ou baixo impacto ambiental.

- Áreas de Reserva Legal (RL) área localizada no interior de uma propriedade ou posse rural, delimitada nos termos do artigo 12, do Código Florestal, com a função de assegurar o uso econômico de modo sustentável dos recursos naturais do imóvel rural, auxiliar a conservação e a reabilitação dos processos ecológicos e promover a conservação da biodiversidade, bem como o abrigo e a proteção de fauna silvestre e da flora nativa, são áreas delimitadas, passíveis de intervenção, ou seja, nelas admite-se a exploração econômical mediante manejo sustentável, previamente aprovado pelo órgão competente do Sisnama, de acordo com as modalidades previstas no artigo 20 do Código florestal.

\section{Artigos que discutem as áreas de Preservação Permanente Lei 12.651/12}

As chamadas APPs são os terrenos mais vulneráveis em propriedades particulares rurais ou urbanas. Como têm uma maior probabilidade de serem palco de deslizamento, erosão ou enchente, devem ser protegidas. É o caso das margens de rios e reservatórios, topos de morros, encostas em declive 
ou matas localizadas em leitos de rios e nascentes.

As APPs são de grande importância, pois visa o equilíbrio ecológico e são definidas conforme legislação vigente (GRANZIERA, 2014):

Art. $4^{\circ}$ - Considera-se Área de Preservação Permanente, em zonas rurais ou urbanas:

I - as faixas marginais de qualquer curso d'água natural perene e intermitente, excluídos os efêmeros, desde a borda da calha do leito regular, em largura mínima de:a) 30 (trinta) metros, para os cursos d'água de menos de 10 (dez) metros de largura;

b) 50 (cinquenta) metros, para os cursos d'água que tenham de 10 (dez) a 50 (cinquenta) metros de largura;

c) 100 (cem) metros, para os cursos d'água que tenham de 50 (cinquenta) a 200 (duzentos) metros de largura;

d) 200 (duzentos) metros, para os cursos d'água que tenham de 200 (duzentos) a 600 (seiscentos) metros de largura;

e) 500 (quinhentos) metros, para os cursos d'água que tenham largura superior a 600 (seiscentos) metros;

II - as áreas no entorno dos lagos e lagoas naturais, em faixa com largura mínima de:

a) 100 (cem) metros, em zonas rurais, exceto para o corpo d'água com até 20 (vinte) hectares de superfície, cuja faixa marginal será de 50 (cinquenta) metros;

b) 30 (trinta) metros, em zonas urbanas;

III - as áreas no entorno dos reservatórios d'água artificiais, decorrentes de barramento ou represamento de cursos d'água naturais, na faixa definida na licença ambiental do empreendimento;

IV - as áreas no entorno das nascentes e dos olhos d'água perenes, qualquer que seja sua situação topográfica, no raio mínimo de 50 (cinquenta) metros; (Redação dada pela Lei no 12.727, de 2012).

$\mathrm{V}$ - as encostas ou partes destas com declividade superior a $45^{\circ}$, equivalente a $100 \%$ (cem por cento) na linha de maior declive;

VI - as restingas, como fixadoras de dunas ou estabilizadoras de mangues;

VII - os manguezais, em toda a sua extensão;
VIII - as bordas dos tabuleiros ou chapadas, até a linha de ruptura do relevo, em faixa nunca inferior a 100 (cem) metros em projeções horizontais;

IX - no topo de morros, montes, montanhas e serras, com altura mínima de 100 (cem) metros e inclinação média maior que $25^{\circ}$, as áreas delimitadas a partir da curva de nível correspondente a $2 / 3$ (dois terços) da altura mínima da elevação sempre em relação à base, sendo esta definida pelo plano horizontal determinado por planície ou espelho d'água adjacente ou, nos relevos ondulados, pela cota do ponto de sela mais próximo da elevação;

$\mathrm{X}$ - as áreas em altitude superior a 1.800 (mil e oitocentos) metros, qualquer que seja a vegetação;

XI - em veredas, a faixa marginal, em projeção horizontal, com largura mínima de 50 (cinquenta) metros, a partir do espaço permanentemente brejoso e encharcado.

Como se pode observar, a proteção legal destinada as APPs contemplam todos os tipos de solo e paisagens existentes no Brasil, o objetivo é para proteger as áreas que consiste na proteção e conservação dos solos, proteção à fauna, flora e manutenção da recarga hídrica.

Importante observar que o novo Código Florestal traz inovação no que diz respeito à APP e é autorizada, exclusivamente, a continuidade das atividades agrossilvipastoris ${ }^{8}$, de ecoturismo e de turismo rural nas áreas rurais consolidadas até 22 de julho de 2008.

Entende-se como área rural consolidada a área de imóvel rural com ocupação antrópica preexistente a 22 de julho de 2008, com edificações, benfeitorias ou atividades agrossilvipastoris, admitida, neste último caso, a adoção do regime de pousio.

Em todas as situações contempladas pelo novo código onde se é permitida a exploração de APPs é obrigatória de alguma maneira, a recomposição da área degradada, utilizando à adoção de técnicas de conservação do solo e da água que visem à mitigação dos eventuais impactos. Nos imóveis rurais, com ocupação antrópica das APPs posterior a 22 de julho de 2008, não é permitida a manutenção do uso consolidado, sendo obrigatória a recomposição integral com vegetação nativa.

\footnotetext{
${ }^{8}$ Florestas com agricultura e pecuária simultânea ou sequencial
} 
Para os assentamentos do Programa de Reforma Agrária, a recomposição de áreas consolidadas em APPs ao longo ou no entorno de cursos d'água, lagos e lagoas naturais, deverão observar as exigências estabelecidas no artigo 61-A, da Lei 12.551/12 atentando para os limites de cada área demarcada individualmente, objeto de contrato de concessão de uso, até a titulação por parte do Instituto Nacional de Colonização e Reforma Agrária - INCRA.

\section{As Áreas de Reserva Legal}

As áreas de RL estão delimitadas no seguinte artigo do Código Florestal:

Art.12 - Todo imóvel rural deve manter área com cobertura de vegetação nativa, a título de Reserva Legal, sem prejuízo da aplicação das normas sobre as Áreas de Preservação Permanente, observados os seguintes percentuais mínimos em relação à área do imóvel, excetuados os casos previstos no art. 68 desta Lei:

I - localizado na Amazônia Legal:

a) $80 \%$ (oitenta por cento), no imóvel situado em área de florestas; b) $35 \%$ (trinta e cinco por cento), no imóvel situado em área de cerrado;

c) $20 \%$ (vinte por cento), no imóvel situado em área de campos gerais;

II - localizado nas demais regiões do País: 20\% (vinte por cento).

$\S 1^{\circ}$ Em caso de fracionamento do imóvel rural, a qualquer título, inclusive para assentamentos pelo Programa de Reforma Agrária, será considerada, para fins do disposto do caput, a área do imóvel antes do fracionamento.

É possível incluir a APP no cálculo do percentual da RL do imóvel, desde que não implique a conversão de novas áreas para o uso alternativo do solo, ou que a área a ser computada esteja conservada ou em processo de recuperação, conforme comprovação do proprietário ao órgão estadual integrante do SISNAMA e o proprietário ou possuidor tenha requerido inclusão do imóvel no CAR.

Com o advento do novo Código Florestal em 2012, a exigência de averbação em cartório da área de RL deixou de ser obrigatória desde que haja o registro no CAR.

Instituído em 2012 com a Lei do Código Florestal (Lei Federal no
12.651/12), o CAR teve sua regulamentação em 05 de maio de 2014, sendo tratado como instrumento de controle, monitoramento, planejamento ambiental e combate ao desmatamento.

Seu objetivo é auxiliar o processo de regularização ambiental de propriedades rurais, garantindo o cumprimento do dever de defender e preservar o meio ambiente conforme estabelece a Constituição Federal.

O registro do imóvel rural no CAR é público, eletrônico, de abrangência nacional e de caráter obrigatório. $\mathrm{O}$ cadastro é realizado na plataforma web do Sistema de Cadastro Ambiental Rural (SICAR) por meio de informações da planta do imóvel rural: áreas de preservação permanente, áreas de reserva legal; áreas produtivas, áreas degradadas, perímetro, entre outras.

No caso das pequenas propriedades rurais (considerando o número de módulo fiscal e o município de localização), os órgãos ambientais estaduais são responsáveis por oferecer auxílio para a realização do cadastro, em contrapartida, para as demais propriedades o cadastro deve ser realizado, exclusivamente, através da contratação de responsável técnico.

Para que a área de RL seja instituída são necessários alguns estudos, levando em consideração o plano de bacia hidrográfica o Zoneamento Ecológico-Econômico (ZEE), a formação de corredores ecológicos com outra RL, com APPs, com Unidades de Conservação ou com outras áreas legalmente protegidas, que são as áreas de maior importância para a conservação da biodiversidade e as áreas de maior fragilidade ambiental.

Admite-se a exploração econômica da RL, mediante manejo sustentável, previamente aprovado pelo órgão ambiental competente do SISNAMA.

Para isso, serão adotadas práticas de exploração seletiva nas modalidades de manejo sustentável sem o propósito comercial para consumo na propriedade e manejo sustentável para exploração florestal com propósito comercial. O manejo florestal sustentável da vegetação da RL com propósito comercial depende de autorização do órgão competente e deverá atender as seguintes diretrizes e orientações: não descaracterizar a cobertura vegetal e não prejudicar a conservação da vegetação nativa da área; assegurar a manutenção da diversidade das espécies; conduzir o manejo de espécies exóticas com a adoção de medidas que favoreçam a regeneração de espécies nativas.

As áreas de RL são de extrema importância, pois ajudam a preservar a biodiversidade e com os corredores ecológicos que se formam entre as propriedades é possível à circulação dos animais possibilitando sua sobrevivência. 


\section{Recursos hídricos e outorga da Água}

A água sempre foi considerada elemento primordial para a sobrevivência da espécie humana, esse tema tem sido tratado em nosso sistema legal, constitucional e infraconstitucional, visando a proteção da saúde humana, onde a sustentabilidade deste recurso natural torna-se indispensável ao crescimento econômico do País. Salienta-se que, ainda na época do Brasil - colônia, sob a égide das Ordenações do Reino já existiam institutos para regular o regime das águas existentes em nosso território (BRAGA, 2002).

Ao longo dos séculos as Constituições e outras normas versam sobre o direito ao uso da água seja ela superficial ou subterrânea (POMPEU, 2002; ANTUNES, 2002), cabe destacar que entre as constituições brasileiras, a de 1988 foi considerada a constituição mais moderna e liberal que o país teve (GRANZIEIRA, 2001), dedicando um capítulo exclusivamente ao Meio Ambiente, o que é raridade no mundo (DRUMOND, 1988).

Embora o Brasil possua uma das maiores reservas de água doce do planeta, somente nas últimas décadas, os recursos hídricos despertaram maior atenção na esfera governamental. O uso sustentável da água é uma questão que tem provocado grande preocupação nos planejadores, sendo considerada como uma das bases de desenvolvimento da sociedade moderna.

A Lei $n^{\circ}$ 9.433, de 08 de janeiro de 1997, criou a Política Nacional dos Recursos Hídricos, que reconhece a água como um bem finito e vulnerável, além de indicar princípios básicos, instrumentos e formas de organização para a gestão compartilhada do uso da água. Tem como objetivo assegurar à atual e às futuras gerações a necessária disponibilidade de água em padrões de qualidade adequados aos respectivos usos.

Conhecida como Lei das Águas, Lei 9.433/97, parte do princípio de que a colaboração é fundamental para o delineamento de um futuro mais adequado em termos de disponibilidade hídrica. Define ainda cincos instrumentos essenciais à boa gestão do uso da água: o Plano Nacional de Recursos Hídricos, a Outorga de Direito de Uso dos Recursos, a Cobrança pelo Uso da Água, o Enquadramento dos Corpos d'água em classes de uso e o Sistema Nacional de Informação sobre Recursos Hídricos.

A Lei $n^{0}$ 9.984, de 17 de julho de 2000, dispõe sobre a criação da Agência Nacional de Águas - ANA, entidade federal de implementação da Política Nacional de Recursos Hídricos, integrante do Sistema Nacional de Gerenciamento de Recursos Hídricos, estabelecendo regras para a sua atuação, sua estrutura administrativa e suas fontes de recursos.

No Estado de São Paulo existe ainda a Lei n ${ }^{\circ} 7663 / 91$, Política Estadual de Recursos Hídricos, que estabelece normas de orientação à Política Estadual de Recursos Hídricos, bem como ao Sistema Integrado de Gerenciamento de Recursos Hídricos.

Os recursos hídricos dentro da propriedade poderão ser utilizados mediante outorga concedida pela ANA, quando se tratar de rios federais, ou órgão ambiental equivalente de seu estado, em se tratando de rios estaduais. $\mathrm{O}$ mesmo se aplica à implantação de barragens ou reservatórios conforme legislação específica.

Dentre as situações que exigem outorga, segundo o documento Responsabilidade Ambiental na Produção Agrícola (BUNGE, 2016) destacamos:

- derivação ou captação de água de curso natural ou depósito superficial;

- lançamentos diretos ou indiretos de esgotos e demais resíduos líquidos ou fluidos gasosos, tratados ou não;

- realização de obras hidráulicas;

- realização de serviços de limpeza;

- proteção de margens e desassoreamento de cursos d'água; e

- travessias em cursos d'água.

O regime de outorga de direitos de uso de recursos hídricos tem como objetivos assegurar o controle quantitativo e qualitativo dos usos da água e o efetivo exercício dos direitos de acesso à água. A outorga de direito de uso de recursos hídricos é um instrumento da Política Nacional de Recursos Hídricos por meio do qual o Poder Público autoriza, concede ou permite o usuário a utilizar determinado volume de água sob sua dominialidade por período pré-determinado, nos termos e nas condições expressas em ato administrativo 9 .

\section{Leis de Crimes Ambientais}

A Lei de Crimes Ambientais n 9.605 é de 1998 e é dividida em capítulos. O capítulo 5 trata dos crimes contra o meio ambiente, subdividido em seções que tratam de assuntos específicos. Para o produtor rural, as seções mais importantes são: dos crimes contra a fauna, dos crimes contra a flora e da poluição e outros crimes ambientais.

${ }_{9}^{9} \mathrm{http} / /$ metadados.ana.gov.br/geonetwork/srv/pt/main.home?uuid=a13c9093-34bd-403f-88db-6ffbad2069e6 
Com o surgimento da Lei de Crimes ambientais, a proteção do Meio Ambiente se torna mais efetiva, surgindo penas, agravantes, atenuantes e multas que foram adequadas ao tipo de infração e seu grau de degradação ou prejuízo ao meio ambiente.

Define também, a responsabilidade das pessoas jurídicas pelos danos causados com seus empreendimentos à natureza, permitindo desta forma, que as mesmas se tornem responsabilizadas nas esferas civil, administrativa e penal pelos seus danos ambientais, podendo assim levar o causador do dano à prisão.

Segundo o Supremo Tribunal Federal - STF e o Superior Tribunal de Justiça - STJ, as pessoas jurídicas podem ser responsabilizadas com uma dupla imputação de pessoa jurídica e pessoa física, podendo em certas situações, ocorrer à desconsideração da pessoa jurídica sempre que sua personalidade for obstáculo ao ressarcimento dos prejuízos causados à qualidade do meio ambiente.

\section{Dos Crimes Contra a Fauna}

A Lei 9.605/98 assim define crimes contra a Fauna:

Art.29 - Matar, perseguir, caçar, apanhar, utilizar espécimes de fauna silvestre, nativos ou em rota migratória, sem a devida permissão, licença ou autorização da autoridade competente, ou em desacordo com a obtida.

A lei de Crimes Ambientais considera crime não somente a ação de matar ou caçar animais da fauna silvestre, como também os maus tratos ou quem impede a reprodução destruindo ninhos, crimes estes todos, passiveis de reclusão ou detenção além de pagamento de multa.

A lei contempla ainda outras situações consideradas crimes como, por exemplo, realizar pesca em período de piracema, com explosivos ou substâncias tóxicas, quem vende, expõe à venda, exporta ou adquire, guarda, tem em cativeiro ou depósito, utiliza ou transporta ovos, larvas ou espécimes da fauna silvestre, nativa ou em rota migratória, bem como produtos e objetos dela oriundos, provenientes de criadouros não autorizados ou sem a devida permissão, licença ou autorização da autoridade competente.

A exceção à regra é que a lei não considera crime o abate de animal, quando realizado em estado de necessidade, para saciar a fome do agente ou de sua família, para proteger lavouras, pomares e rebanhos da ação predatória ou destruidora de animais, desde que legal e expressamente autorizado pela autoridade competente, ou ainda por ser nocivo o animal, desde que assim caracterizado pelo órgão competente.

\section{Dos Crimes contra a Flora}

Os crimes contra a flora Brasileira estão definidos no artigo 38 e seguintes da Lei 9605/98

Art.38 - Destruir ou danificar floresta considerada de preservação permanente, mesmo que em formação, ou utilizá-la com infringência das normas de proteção.

Art. 38-A. - Destruir ou danificar vegetação primária ou secundária, em estágio avançado ou médio de regeneração, do Bioma Mata Atlântica, ou utilizá-la com infringência das normas de proteção:

Art.39 - Cortar árvores em floresta considerada de preservação permanente, sem permissão da autoridade competente.

A utilização, degradação e recomposição das APPs, Unidades de Conservação entre outras foi objeto de proteção no Código Florestal e ganho amparo também na Lei de Crimes Ambientais onde esses crimes são passiveis de pena de detenção, reclusão além do pagamento de multa.

Um ponto relevante é o que diz respeito às queimadas que se constituem em crime ao serem realizadas, pois na maioria das vezes perde-se o controle sobre o fogo que atinge áreas de florestas.

Outro crime muito comum esta tipificado no artigo 42 da Lei 9605/98:

Art.42 - Fabricar, vender, transportar ou soltar balões que possam provocar incêndios nas florestas e demais formas de vegetação, em áreas urbanas ou qualquer tipo de assentamento humano:

Ver os balões no céu chama a atenção e pode até ser bonito, porém ao cair ele pode ocasionar um incêndio de grandes proporções e prejuízos incalculáveis ao meio ambiente.

Outro ponto tipificado pela referida lei, diz respeito a extrair de dentro das florestas os produtos nela contidos como, por exemplo, pedra, areia, cal ou qualquer espécie de minerais, cortar ou transformar em carvão madeira de lei, receber ou adquirir, para fins comerciais ou industriais, madeira, lenha, carvão e outros produtos de origem vegetal, sem exigir a exibição de licença 
do vendedor, outorgada pela autoridade competente, e sem munir-se da via que deverá acompanhar o produto até final beneficiamento é considerado crime ambiental.

Incorre ainda em crime ambiental, aquele que impede ou dificulta a regeneração natural de florestas e demais formas de vegetação.

\section{Da Poluição e outros Crimes Ambientais}

$\mathrm{O}$ artigo 54 da lei 9605/98 traz a possibilidade de se punir o crime na forma culposa com detenção de seis meses a um ano e multa.

Art.54 - Causar poluição de qualquer natureza em níveis tais que resultem ou possam resultar em danos à saúde humana, ou que provoquem a mortandade de animais ou a destruição significativa da flora.

Se do crime resultar numa área, urbana ou rural, imprópria para a ocupação humana, causar poluição atmosférica que provoque a retirada, ainda que momentânea, dos habitantes das áreas afetadas, ou que cause danos diretos à saúde da população, causando poluição hídrica que torne necessária a interrupção do abastecimento público de água de uma comunidade, dificultando ou impedindo o uso público das praias, o lançamento de resíduos sólidos, líquidos ou gasosos, ou detritos, óleos ou substâncias oleosas, em desacordo com as exigências estabelecidas em leis ou regulamentos, a pena passa a ser de reclusão de um a cinco anos.

As queimadas são possíveis desde que obedeçam a situações específicas com o controle e manejo. A exploração florestal também é possível respeitando a legislação específica e com as devidas autorizações para exploração.

Quando mencionamos o uso de agrotóxicos, a Lei 7.801/89, em seu artigo $2^{\circ}$ assim define:

\section{I - agrotóxicos e afins:}

a) os produtos e os agentes de processos físicos, químicos ou biológicos, destinados ao uso nos setores de produção, no armazenamento e beneficiamento de produtos agrícolas, nas pastagens, na proteção de florestas, nativas ou implantadas, e de outros ecossistemas e também de ambientes urbanos, hídricos e industriais, cuja finalidade seja alterar a composição da flora ou da fauna, a fim de preservá-las da ação danosa de seres vivos considerados nocivos;
A partir de 1970 houve a intensificação do uso de agrotóxicos no País, porém algumas regras de uso e manipulação desses produtos até os dias atuais não são observadas colocando em risco o trabalhador rural pelo uso direto desses agrotóxicos e o consumidor de um modo geral que consome os produtos produzidos sem o devido respeito as normas.

A legislação exige para o manuseio de agrotóxicos o uso de EPI Equipamento Individual de Proteção, além de um descarte de modo correto das embalagens vazias visando uma maior proteção ao trabalhador, bem como ao meio ambiente.

A larga utilização de agrotóxicos no processo de produção rural, entre outras aplicações, tem trazido uma série de transtornos e modificações para o ambiente, seja pela contaminação das comunidades de seres vivos que o compõem, seja pela sua acumulação nos segmentos bióticos e abióticos dos ecossistemas (biota, água, ar, solo, sedimentos etc.) (PERES; MOREIRA, 2003), afetando as criações e animais domésticos, as populações humanas pela ingestão de plantas e alimentos contaminados por agrotóxicos, além do impacto em comunidades e ecossistemas próximos às áreas de plantações e pastos, onde estes produtos são utilizados.

Para um sistema agrícola ser sustentável, efeitos ambientais adversos da produção agrícola devem ser minimizados, enquanto a competitividade e o lucro devem ser mantidos ou evidenciados. A degradação da qualidade de águas subterrâneas e superficiais tem sido identificada como a principal preocupação no que diz respeito ao impacto da agricultura no ambiente. Esta degradação pode ocorrer como resultado do lançamento de produtos químicos agrícolas, ou organismos biológicos, nas águas superficiais e sua movimentação em direção às águas subterrâneas (ZEBARTH, 1999)

Existem várias ações que o produtor rural pode realizar para melhorar e/ou integrar o meio ambiente a sua produção obtendo maior e melhor qualidade com menor impacto ambiental, como por exemplo o cultivo em nível, a rotação de culturas, controle da erosão, utilização da água de modo a garantir seus ciclos e aproveitar ao máximo seu potencial, conduzindo-a de modo a infiltrar-se ao máximo na terra, favorecendo a umidade do solo

A lei de crimes ambientais contemplam várias situações consideradas crimes, portanto é necessário buscar orientação junto aos órgãos competentes, antes de realizar alguma atividade, pois caso seja necessário, será expedido as licenças ambientais ou autorizações pertinentes a cada atividade. 


\section{Atividade produtiva na propriedade rural}

A atividade produtiva na propriedade rural requer cuidados e observância a legislação ambiental. O primeiro passo é com relação a regularização ambiental de qualquer atividade da propriedade, além de obrigatória, constitui-se em uma medida essencial para a sustentabilidade socioambiental.

Não se trata apenas de cumprimento da legislação ambiental, são medidas que após cumpridas representam uma grande oportunidade para a diminuição dos custos de produção, e para a melhora da qualidade de vida dos seres humanos e das demais formas vivas.

Desta forma a observância da Legislação ambiental possibilita, também, o surgimento de novos negócios. Ao mesmo tempo, favorece a conservação do maior patrimônio do produtor: sua propriedade com o patrimônio natural nela contido, como o solo, a água, o ar, os vegetais, os fungos, as bactérias e os animais, além de todas as variações genéticas existentes dentro de cada espécie viva.

Além da regularização pertinente as APPs e área de RL entre outras, a atividade agrícola exige alguns cuidados com a propriedade rural, a saúde do trabalhador, as práticas utilizadas no cultivo e a proteção ao meio ambiente.

Algumas atividades costumeiras realizadas pelo produtor rural tais como a queimada, exploração das florestas e matas, uso de agroquímicos entre outras necessitam de uma regulamentação para serem realizadas.

Essas atividades realizadas sem controle ou a devida autorização legal podem ocasionar sérios danos ao meio ambiente como, por exemplo, a destruição das florestas, principalmente próximas às nascentes, o que contribui para o assoreamento dos rios e a perda de solo e de seus nutrientes, com o consequente entupimento das calhas dos rios, o que, frequentemente, acarreta enchentes, perdas da biodiversidade e de bens econômicos.

Com relação as queimadas elas liberam material em suspensão e particulado na atmosfera contribuindo para a poluição do ar, ao mesmo tempo que provocam a morte de uma série de formas vivas, além de empobrecer o solo e representar $75 \%$ da emissão de $\mathrm{CO}_{2}$.

$\mathrm{O}$ uso indiscriminado e/ou sua forma irregular de agrotóxicos prejudica não só o ambiente (a água, o solo, o ar, etc.), mas também a saúde da pessoa que os manipula. O cumprimento da legislação ambiental e a adoção de práticas agroecológicas, reduzem a necessidade do uso desses produtos, $\mathrm{o}$ que reflete positivamente nos preços da produção, bem como, no aumento da produtividade do solo.
Após a regularização da propriedade o produtor rural deve regularizar as ações que desenvolve em sua propriedade, sendo necessário verificar o que ela necessita, por exemplo no caso do Licenciamento Ambiental (embora não seja exigido em todos os Estados), é importante que o licenciamento seja feito antes do início das atividades agrícolas, devido ao caráter potencialmente degradador destas atividades. O mesmo vale para as propriedades localizadas em zonas de amortecimento das Unidades de Conservação - UCs, e nas Áreas de Proteção Ambiental (APA), nesse caso a regularização deve-se obter a licença através do órgão ambiental competente para licenciar a localização, a instalação, a ampliação e a operação dessas atividades.

Cada caso será analisado de acordo com disposições legais regulamentares e normas técnicas. A licença é fundamental para as atividades que utilizem recursos ambientais que possam ser caracterizadas como poluidoras ou degradadoras do meio ambiente, e estão basicamente dispostas na Lei Federal no 6.938/1981, Resoluções Conama no 01/86 e n 237/1997 e legislação estadual pertinente.

Para que o produtor rural utilize a motosserra em sua propriedade é necessário que a máquina e o operador sejam registrados no IBAMA, fato este, nem sempre observado pelo usuário.

\section{Considerações finais}

A Política Nacional do Meio Ambiente criada em 1981, prevê a preservação, a melhoria e a recuperação do meio ambiente, teve seus interesses reforçados na Constituição Federal de 1988, e impõe ao Poder Público e à coletividade o dever de defender e preservar o meio ambiente para as presentes e futuras gerações.

Nota-se que a evolução da legislação ambiental referente à proteção ambiental é resultado da transformação da visão do legislador quanto à criação de leis de mitigação de impactos e de prevenção de sua ocorrência.

A preocupação ambiental no Brasil sempre esteve presente na legislação de forma sucinta em um país de dimensões continentais tão grande, a responsabilidade com a biodiversidade e os recursos naturais, demandam grande destaque e são de extrema importância, dado a isso os legisladores dedicaram um capítulo, exclusivo, ao Meio Ambiente na Constituição Federal de 1988. 
As mudanças ocorridas no Código Florestal Lei 12.651/2012 levantou uma série de debates e discussões entre os que visavam a qualidade ambiental e os que defendiam a produção agrícola e a pecuária. Entre os principais pontos discutidos, o tema RL, ficou em destaque, haja vista sua grande importância ambiental.

Como já citado, a RL é um instituto jurídico que visa à proteção ao meio ambiente, que possui sua função socioambiental, onde o proprietário poderá usar de forma consciente seus recursos.

Desta forma, surgiu a preocupação de proteger as florestas e todos os seus ecossistemas e biomas que ali existem, e que estavam sendo totalmente destruídos pela ambição da alta produção e exploração desses recursos naturais.

As alterações trazidas pelo novo código ambiental, também trouxeram mudanças nas APPs, sendo a alteração mais discutida, a inclusão desta área no computo da área de RL.

Os percentuais de terra destinados as RL não sofreram alteração, contudo, a averbação junto a matrícula do imóvel não é mais obrigatória e é necessário o cadastramento junto ao CAR.

Para os assentamentos de Reforma Agrária, o computo da área de RL será considerado porção de terra sem o seu fracionamento.

Já no que diz respeito as APPs em razão de sua função ambiental, essas são de utilização muito restrita. Não são intocáveis, mas somente pode haver intervenção nos casos de utilidade pública, interesse social ou baixo impacto ambiental.

Aliadas ao Código Florestal, tem-se diversas leis que tipificam os crimes ambientais, assim como a Lei 9.605/88, que visa a proteção e manutenção do meio ambiente, implementando multas e penas para os infratores que cometem algum dano ou prejuízo ao meio ambiente.

A proteção ao meio ambiente ainda encontra guarida na Constituição Federal em seu artigo 225, o qual ficou estabelecido que "todos tem direito a um meio ambiente equilibrado, sendo atribuído ao Poder Público e a sociedade, o dever de protegê-lo e preservá-lo”.

Segundo Silva (2011), a legislação ambiental no país é ampla e pode ser considerada suficiente para garantir as condições de preservação do meio ambiente, porém, a letra da lei por si só não basta, sendo necessários instrumentos legais que garantam sua aplicabilidade, tais como a necessidade de imposição de multas em caso de desrespeito e fiscalização constante.
Não há uma fórmula pronta e conceitos acabados para se alcançar o ápice da conscientização da comunidade. Acreditamos que uma relação de trabalho sério na busca da transformação social, mediante o exercício constante da cidadania ativa, possa resultar num passo importante para se galgarem alguns degraus na evolução humana numa vida social mais digna.

Nas palavras de Santos (2003) "reconhecemos que a educação é um processo moroso e que muitas vezes não consegue responder aos problemas mais imediatos".

Porém não basta simplesmente atender às normas legais, sendo necessário que o produtor rural contribua com boas práticas agrícolas para o desenvolvimento sustentável e agir com maior responsabilidade socioambiental, atendendo às normas trabalhistas, sanitárias e ambientais, contribuindo desta forma, para a melhoria da qualidade de vida das pessoas envolvidas diretamente na produção. Assim como também, toda a sociedade

A importância da preservação ambiental e a conscientização de toda a sociedade em conjunto com todas as leis, decretos e normas, sejam elas: Estaduais, Municipais ou Federais, as quais garantirão melhor qualidade de vida todos, possibilitando que as futuras gerações possam utilizar os recursos naturais hoje disponíveis, diga-se, o desenvolvimento sustentável.

Desta forma, o proprietário rural contribuirá para a conservação do meio ambiente, minimizando impactos com responsabilidade social, sendo possível alcançar o desenvolvimento sustentável com a adoção das melhores práticas agrícolas, aliado a pesquisas científicas, assim como, o conhecimento de comunidades tradicionais e o cumprimento da legislação ambiental e social.

\section{Referências Bibliográficas}

ANTUNES, P. B. Direito Ambiental. 6.ed. Rio de Janeiro: Lumen Juris, 2002.

ALVES, I. O novo Código Florestal. Disponível em: $<$ http://isabellealves. jusbrasil.com.br/artigos/111697485/o-novo-codigo-florestal $>$. Acesso em: 15 mar. 2016.

BRAGA, B.; REBOUÇAS, A. da C. Águas Doces no Brasil: Capital ecológico, uso e conservação. São Paulo: Escrituras, 2002. 
BARROSO, L. R. O Direito Constitucional e a efetividade de suas normas. 3.ed. Rio de Janeiro: Renovar, 1996.

BONAVIDES, P. Curso de Direito Constitucional. 4.ed. São Paulo: Malheiros, 1993.

BRASIL. Constituição da República Federativa do Brasil de 1988. Disponível em: <http://www.planalto.gov.br/ccivil_03/constituicao/ constituicaocompilado.htm>. Acesso em: 15 mar. 2016.

BRASIL. Decreto $\mathbf{n}^{\circ} \mathbf{3 . 1 7 9}$, de 21 de setembro de 1999. Especifica as sanções aplicáveis ás condutas e atividades lesivas ao meio ambiente. Disponível em: $<$ http://www.planalto.gov.br/ccivil/leis/L9605.htm>. Acesso em: 10 mar. 2106

BRASIL. Lei $\mathbf{n}^{\circ} \mathbf{1 2 . 6 5 1}$, de $\underline{25}$ de maio de 2012. Dispõe sobre a proteção da vegetação nativa; altera as Leis $\mathrm{n}^{\mathrm{os}} \mathbf{6 . 9 3 8}$, de 31 de agosto de 1981 , 9.393, de 19 de dezembro de 1996, e 11.428, de 22 de dezembro de 2006; revoga as Leis $n^{\text {os }} 4.771$, de 15 de setembro de 1965, e 7.754, de 14 de abril de 1989, e a Medida Provisória no 2.166-67, de 24 de agosto de 2001; e dá outras providências. Disponível em: <http://www.planalto.gov.br/ ccivil_03/ ato2011-2014/2012/lei/112651.htm>. Acesso em: 12 fev.2016.

BRASIL. Lei ${ }^{\circ}$ 4.771, de 15 de setembro de 1965 . Institui o novo código florestal. Disponível em: <http://www.planalto.gov.br/Ccivil 03/LEIS/ L4771.htm>. Acesso em: 15 mar. 2016.

BRASIL. Lei n ${ }^{\circ}$ 9.605, de 12 de fevereiro de 1998. Dispõe sobre as sanções penais e administrativas derivadas de condutas e atividades lesivas ao meio ambiente, e dá outras providências. Disponível em: $<$ http://www.planalto. gov.br/ccivil_03/leis/19605.htm>. Acesso: 15 mar. 2016.

BUNGE. Responsabilidade ambiental na produção agrícola. Disponível em: http://www.bunge.com.br/downloads/sustentabilidade/cartilha_RA.pdf. Acesso em: 15 mar. 2016.

DRUMMOND, J. A. A Legislação Ambiental Brasileira de 1934 a 1988: comentários de um cientista ambiental simpático ao conservacionismo. Ambiente \& Sociedade, n.3-4, p.127-148, 1998/1999.

FABRIZ, D. C. A estética do Direito. Rio de Janeiro: Del Rey, 2004.

FERREIRA FILHO, M. G. Comentários à Constituição Brasileira de 1988. São Paulo: Saraiva 1997, v. 1.

GRANZIERA, M.L.M. Direito ambiental, 3. ed. São Paulo: Saraiva, 2014.

GRANZIEIRA, M.L.M. Direito de Águas e Meio Ambiente. São Paulo: Ícone, 1993.

KAPRA, F. O ponto de mutação: a ciência, a sociedade e a cultura emergente. São Paulo: Cultrix, 2005.

MAZZILLI, H.N. A defesa dos interesses difusos em juízo: meio ambiente, consumidor, patrimônio cultural, patrimônio público e outros interesses. 25.ed. São Paulo: Saraiva, 2012.

MILARÉ, E. Direito administrativo e meio ambiente. 4.ed. São Paulo: Revista dos Tribunais, 2000.

MOREIRA, R. J. Críticas ambientalistas à Revolução Verde. In: World Congress of Rural Sociology - IRSA e XXXVII Brazilian Congress of Rural Economic and Sociology - Sober. Anais... Rio de Janeiro, 2000.

OSBORNE, D. Reinventando o Governo: como o espírito empreendedor está transformando o setor público. Brasília: MH Comunicações, 2006.

POMPEU, C. T. Regime Jurídico da Política das Águas Públicas. São Paulo: CETESB, 1976.

PERES, F.; MOREIRA, JC. (Orgs.) É veneno ou é remédio?: agrotóxico, saúde e ambiente. Rio de Janeiro: Editora FIOCRUZ, 2003.

SANTOS, J. E.; SATO, M. Universidade e Ambientalismo: encontros não são despedidas. In: SANTOS, J. E.; SATO, M. A contribuição da educação 
ambiental à esperança de Pandora. 2.ed. São Carlos: Ed. Rima, 2003.

SILVA, A. M. R. C. Análise do assentamento Bela Vista do Chibarro (Araraquara-SP): legislação incidente, uso e ocupação do solo e percepção ambiental. Araraquara, 2011. Dissertação (Mestrado em Desenvolvimento Regional e Meio Ambiente) - Centro Universitário de Araraquara.

SILVA, J.A. Direito Ambiental Constitucional. São Paulo: Malheiros, 1994.

WALDMAN, M. Ecologia e movimentos sociais: breve fundamentação. In: VIANA, A. (Org.). Hidrelétricas, Ecologia e Progresso. Rio de Janeiro: CEDI, 2007.

UMEDA, C. Y. L. et al. Uso de sensoriamento remoto na identificação de corredores ecológicos: estudo de caso da Bacia Hidrográfica do Rio Formoso, Bonito, MS. Eng Sanit Ambient., v.20, n.4, p.551-557, out./ dez. 2015.

ZEBARTH, B. J. Improved manure, fertilizer and pesticide management for reduced surfaceand groundwater. Canadá: The Pacific Agri-Food Research Centre, 1999. Disponível em: http://res.agr.ca/agassiz/studies/ zebasdb.htm. Acesso em: 12 fev. 2016. 